\title{
Interactions Between Fusarium verticillioides, Aspergillus flavus, and Insect Infestation in Four Maize Genotypes in Lowland Africa
}

\author{
K. F. Cardwell, J. G. Kling, B. Maziya-Dixon, and N. A. Bosque-Pérez
}

First, second, and third authors: International Institute of Tropical Agriculture (IITA), PMB 5320 Oyo Rd, Ibadan, Nigeria; fourth author: Department of Plant, Soil, and Entomological Sciences, University of Idaho, Moscow 83844-2339. Accepted for publication 13 November 1999.

\begin{abstract}
Cardwell, K. F., Kling, J. G., Maziya-Dixon, B., and Bosque-Pérez, N. A. 2000. Interactions between Fusarium verticillioides, Aspergillus flavus, and insect infestation in four maize genotypes in lowland Africa. Phytopathology 90:276-284.

An experiment was designed to compare cycles of selection of four maize genotypes for ear- and grain-quality characteristics, interactions with Aspergillus flavus and Fusarium verticillioides infection, and insect ear infestation in two seasons. Mean infection levels by A. flavus and $F$. verticillioides were significantly higher in inoculated rows than in the controls. The $F$. verticillioides-inoculated rows had significantly more coleopteran beetles and lepidopteran borers per ear than the controls and A. flavus-inoculated rows. Genotypes and cycles of selection within genotype were not different with respect to number of insects or percent fungal incidence in the ear, but they were different for husk extension,
\end{abstract}

ABSTRACT field weight, 100-grain weight, and grain density. Inoculation with either fungus resulted in significantly higher percentage of floaters (i.e., loss of grain density) and lower grain weight than the controls. Aflatoxin (B1 and B2) in A. flavus-inoculated rows averaged $327 \mathrm{ppb}$ in the first season and $589 \mathrm{ppb}$ in the second (dryer) season. Fumonisin levels in F. verticillioides-inoculated rows did not differ between seasons, with an average of $6.2 \mathrm{ppm}$ across seasons. In the noninoculated control rows, fumonisin was significantly higher in the first $(5.3 \mathrm{ppm})$ than in the second $(3.1 \mathrm{ppm})$ season. For all genotypes, husk extension and yield parameters decreased in the fungal-inoculated treatments. General ear-rot scoring was significantly correlated with incidence of $F$. verticillioides in kernels and grain-weight loss but not with A. flavus in the grain.

Additional keywords: Eldana saccharina, maize postharvest pests, Mussidia nigrivenella, Sesamia calamistis, stem borers, West Africa.
Maize is particularly vulnerable to degradation by mycotoxigenic fungi $(23,31)$. Two mycotoxigenic fungi that are prevalent in maize in Africa are Aspergillus flavus Link:Fr., which produces aflatoxins $(11,12,42,48)$, and Fusarium verticillioides Sacc. (Nirenberg) (synonym $F$ moniliforme Sheld.), which produces the toxin fumonisin $(16,26)$. Many fungi enter the ear through the silk channel (20), often carried in by Lepidoptera and Coleoptera spp. $(3,9,36)$. A. flavus spores land on the silk, germinate, and enter the cob just prior to pollination and subsist on senescent silks within the husks indefinitely $(8,27)$. Fusarium spp. spores land on the silk, germinate, and enter the ear after pollination $(17,31,36)$. Both may invade kernels directly through weak spots in the pericarp, such as silk scars and stress cracks, through the pedicel, or through damage due to insect feeding sometime before harvest $(15,35$, 39,50).

Lepidopterous borers are considered among the most important insect pests of maize in Africa. Three stem borer species, Sesamia calamistis Hampson (Noctuidae), Busseola fusca Fuller (Noctuidae), and Eldana saccharina Walker (Pyralidae) are known to cause significant yield loss in West Africa (5). These borer species feed on stems of plants as well as maize kernels. The maize cob borer, Mussidia nigrivenella Ragonot (Pyralidae), causes serious damage to maize ears, especially in the Guinea savannas of West Africa $(4,42)$. Larvae of $M$. nigrivenella start their damage from the tip of the ear and bore into kernels, producing abundant frass and silk. The maize weevil, Sitophilus zeamais (Coleoptera: Curculionidae) is an important pest of stored maize grain in West

Corresponding author: K. F. Cardwell; E-mail address: k.cardwell@cgiar.org

Publication no. P-2000-0124-01R

(C) 2000 The American Phytopathological Society
Africa (22). Infestations of the maize weevil often begin in the field before maize is harvested. Other coleopteran species, such as Cathartus quadricollis Guerin-Meneville (Sylvanidae) and Carpophilus sp. (Nitidulidae), also are commonly detected on maize just before harvest (42). Numerous insect species have been implicated in facilitating the dispersal of $A$. flavus and subsequent aflatoxin contamination $(3,28,41,42,50)$ and of $F$. verticillioides and fumonisin contamination in maize (10).

At least four genetically controlled characteristics modulate resistance of maize to the fungi $F$. verticillioides and A. flavus and the toxins they produce: (i) resistance to the infection process through physical barriers, (ii) resistance to fungal growth and toxin production after infection has occurred, (iii) resistance to insect damage, and (iv) tolerance of environmental stress $(13,44,50)$. At the International Institute of Tropical Agriculture (IITA), Ibadan, Nigeria, maize breeders work to provide a range of maize maturity groups and grain types to meet the demands of different end users throughout West Africa. While developing these alternatives, efforts have been made to improve the ear and to eliminate generic "ear rot" for all breeding materials, without specific attention to the etiology of the rot. There has been no specific screening against susceptibility to A. flavus or F. verticillioides; nevertheless, it was expected that constant selection for better agronomic characteristics (better husk cover, reduced ear rot, stress tolerance, and stem borer resistance) would improve the maize populations and concomitantly reduce A. flavus infection and aflatoxin contamination and susceptibility to Fusarium ear rot.

The current study was conducted to assess the effect of cycles of selection of four maize genotypes on fungus infection, insect infestation, and mycotoxin contamination. Currently used maize screening criteria for general ear rot and ear damage by insects were assessed for efficacy in reducing A. flavus, F. verticillioides, and insects during successive breeding cycles. 


\section{MATERIALS AND METHODS}

Seasons. In much of West Africa below latitude $10^{\circ}$ north, the annual rainfall pattern is bimodal, allowing for at least two crops during the year. Our experiment was conducted twice at IITA in Ibadan, Nigeria, in 1996. The first trial was planted on 17 May (season A) and the second on 27 August (season B). The experiment in season A was exposed to the most rainfall $(774 \mathrm{~mm})$, which could be expected to enhance growth of both fungi $(15,30)$. The season B trial had a shortage of rainfall $(474 \mathrm{~mm})$ and required irrigation during the last 45 days.

Maize genotypes. Early and advanced cycles of selection of each of four experimental maize genotypes were evaluated (Table 1). The genotypes were divided into late and early maturity categories. The late genotypes were planted 7 days ahead of the early genotypes, so silking occurred at approximately the same time in all accessions. Genotype Tropical Zea Early (TZE) composite 4, with broad adaptation in the lowland tropics, had undergone four cycles of selection for high yield and good ear characteristics. Genotype Tropical Zea Borer Resistant (TZBR) Eldana 1 was formed in 1988 and selected for resistance to the borer E. sac- charina, using ear and stem damage and husk cover as selection criteria (18). Genotype Pool 16 was originally a population developed at the Centro International de Mejoramiento de Maiz y Trigo (CIMMYT), Mexico, D.F., that exhibited drought tolerance in West Africa, and was improved within the subregion for resistance to maize streak virus and adaptation to the semiarid lowland tropics. Genotype Gbogbe, a local, floury-endosperm cultivar, known for good storability and husk cover, was backcrossed for two generations with the IITA population Tropical Zea Streak Resistant White 1 (TZSR-W-1) to improve yield (19). Selection for the husk cover and milling quality of Gbogbe was made during backcrossing and subsequent selection. For the remainder of the paper, this population will be referred to simply as Gbogbe.

Field design. The trial was a split-plot design conducted during two seasons with three replicates per season. The main plot was a factorial arrangement of two factors: maize genotype and cycle of selection. The subplot was four inoculation treatments. Each genotype-cycle treatment was planted in plots of six rows, $5 \mathrm{~m}$ long. Rows one and six were border rows; row two was inoculated with A. flavus; row three was the A. flavus control row; row four was the $F$. verticillioides control row; and row five was inoculated

TABLE 1. Maize genotypes

\begin{tabular}{llcl}
\hline Population $^{\mathrm{a}}$ & Cycles of selection & $\begin{array}{c}\text { Maturity, grain color, } \\
\text { milling quality }\end{array}$ & \multicolumn{1}{c}{ Selection emphases } \\
\hline TZE composite 4 & C0 and C2 & E, W, SD & Yield, drought tolerance, husk cover, ear rot resistance \\
TZBR Eldana 1 & C0 and C5 & L, M, F/D & Eldana resistance \\
Pool 16 SR & Gusau 1981 and Acr 1990 & E, M, D & Streak resistance, drought tolerance, yield, husk cover \\
Gbogbe $\times$ TZSR-W-1 & C0 and C3 & L, Y, F/Fl & Yield, husk cover, weevil resistance, milling quality \\
\hline
\end{tabular}

a TZE = genotype Tropical Zea Early, TZBR = genotype Tropical Zea Borer Resistant, and TZSR-W-1 = Tropical Zea Streak Resistant White 1.

${ }^{\mathrm{b}} \mathrm{E}=$ early, $\mathrm{L}=$ late, $\mathrm{W}=$ white, $\mathrm{M}=$ mixed, $\mathrm{Y}=$ yellow, $\mathrm{F}=$ flint, $\mathrm{Fl}=$ floury, $\mathrm{SD}=$ semident, and $\mathrm{D}=$ dent.

TABLE 2. Least significant means (LSM) of ear- and grain-quality variables by cycles of selection and fungal inoculation treatments ${ }^{\mathrm{a}}$ in seasons A and B in Ibadan, Nigeria, in 1996, and pairwise differences across seasons

\begin{tabular}{|c|c|c|c|c|c|c|c|c|c|c|c|c|}
\hline $\begin{array}{l}\text { Cycles and } \\
\text { treatments }\end{array}$ & $\begin{array}{l}\mathrm{Af}^{\mathrm{b}} \\
(\%)\end{array}$ & $\begin{array}{l}\mathrm{Fv}^{\mathrm{b}} \\
(\%)\end{array}$ & $\begin{array}{l}\text { Other fungib } \\
\quad(\%)\end{array}$ & $\begin{array}{c}\text { Insect } \\
\text { damage }^{\mathrm{c}}\end{array}$ & $\begin{array}{l}\text { No. of } \\
\text { borers }\end{array}$ & $\begin{array}{l}\text { No. of } \\
\text { beetles }\end{array}$ & Extension $^{\mathrm{e}}$ & $\begin{array}{c}\text { Floaters } \\
(\%)\end{array}$ & $\begin{array}{c}\text { 100-grain } \\
\text { wt (g) }\end{array}$ & $\begin{array}{l}\text { Consumable- } \\
{\text { grain } \mathrm{wt}^{\mathrm{f}}}^{\mathrm{s}}\end{array}$ & $\begin{array}{c}\text { Field wt }{ }^{\mathrm{g}} \\
(\mathrm{kg} / \mathrm{ha})\end{array}$ & $\begin{array}{l}\text { Ear rot } \\
\text { rating }^{\text {h }}\end{array}$ \\
\hline \multicolumn{13}{|l|}{ Season A } \\
\hline Cycle E & 31.6 & 30.6 & 2.0 & 1.9 & 4.7 & 14.9 & 2.7 & 45.9 & 28.3 & 24.8 & 3,769 & 2.9 \\
\hline Trt Af & 77.4 & 8.9 & 0.9 & 1.8 & 3.7 & 9.9 & 2.5 & 46.7 & 27.9 & 22.7 & 3,774 & 3.1 \\
\hline Trt C1 & 27.0 & 14.2 & 6.2 & 1.7 & 5.5 & 13.2 & 2.5 & 40.1 & 30.0 & 26.9 & 4,019 & 2.6 \\
\hline Trt C2 & 18.8 & 32.1 & 2.5 & 1.5 & 4.8 & 13.5 & 2.4 & 37.2 & 27.9 & 27.4 & 3,933 & 2.5 \\
\hline Trt Fv & 6.8 & 71.4 & 0.4 & 2.8 & 7.8 & 27.4 & 2.6 & 51.0 & 28.8 & 20.9 & 3,477 & 3.7 \\
\hline Cycle E & 14.8 & 22.8 & 0.1 & 1.3 & 0.0 & 13.7 & 2.6 & 41.5 & 25.4 & 23.4 & 3,173 & 2.8 \\
\hline Cycle A & 18.2 & 24.4 & 0.1 & 1.3 & 0.4 & 14.0 & 2.3 & 31.1 & 29.7 & 24.8 & 3,894 & 3.4 \\
\hline Trt Af & 35.2 & 8.7 & 0.0 & 1.5 & 0.0 & 7.4 & 2.6 & 40.4 & 28.5 & 21.2 & 3,191 & 3.8 \\
\hline Trt C1 & 23.7 & 9.5 & 0.2 & 1.0 & 0.2 & 5.9 & 2.3 & 36.0 & 30.0 & 26.0 & 3,886 & 2.3 \\
\hline Trt C2 & 4.2 & 1.7 & 0.1 & 1.3 & 0.1 & 8.7 & 2.4 & 30.9 & 27.4 & 26.3 & 3,415 & 2.4 \\
\hline Trt Fv & 2.9 & 74.4 & 0.1 & 1.5 & 0.4 & 33.4 & 2.5 & 38.0 & 27.4 & 22.8 & 3,243 & 4.0 \\
\hline \multicolumn{13}{|l|}{ LSM $^{\mathrm{i}}$} \\
\hline $\mathrm{C} 1$ to $\mathrm{C} 2$ & $-14.4 * * *$ & $5.8 * *$ & $-1.9 * * *$ & 0.0 & 0.2 & 1.5 & 0.0 & -2.3 & 0.7 & 0.4 & 6 & 0.0 \\
\hline $\mathrm{C} 1$ to $\mathrm{Fv}$ & $20.9^{* * *}$ & $-62.3 * * *$ & $2.9 * * *$ & $-0.8 * * *$ & -1.3 & $-18.5^{* * *}$ & $-0.2 * *$ & -1.7 & -0.7 & $4.6^{* * *}$ & $546 * * *$ & $-1.2 * *$ \\
\hline $\mathrm{C} 2$ to $\mathrm{Fv}$ & $6.5 * *$ & $-56.5^{* * * *}$ & $1.1^{*}$ & $-0.7 * * *$ & $-1.6^{*}$ & $-7.0 * * *$ & $-0.1^{*}$ & $-4.1^{*}$ & 0.1 & $5.0 * * *$ & $553 * * *$ & $-1.2^{* *}$ \\
\hline
\end{tabular}

a Means of 48 observations per cycle and 24 observations per fungal treatment. Cycle $\mathrm{E}=$ early cycle of selection; cycle $\mathrm{A}=$ advanced cycle of selection. Treatment $(\mathrm{Trt}) \mathrm{Af}=$ inoculation with Aspergillus flavus; $\mathrm{Fv}=$ inoculation with Fusarium verticillioides; $\mathrm{C} 1=$ control adjacent to Af treatment; and $\mathrm{C} 2=$ control adjacent to Fv treatment.

${ }^{\mathrm{b}}$ Percent A. flavus, F. verticillioides, and other fungi in 100 kernels.

${ }^{c}$ Visible ear damage at harvest ( 1 to 5 scale, where 1 is low and 5 is high).

${ }^{\mathrm{d}}$ Mean counts of insects per five ears at harvest.

e Extension of husk beyond end of cob ( 1 to 5 scale, where 1 is good and 5 is poor).

${ }^{\mathrm{f}}$ Consumable grain weight $=100$-grain weight - discolored and insect-damaged grain .

$\mathrm{g}$ Field weight $=$ mean row cob weight.

${ }^{\text {h }}$ Rating of kernels ( 1 to 5 scale, where $1=$ sound and $5=$ damaged $)$.

${ }^{\text {i }}$ Pairwise differences across seasons. Comparisons $(P>t)$ are means of 96 cycle and 48 treatment observations. Levels of significance: $* * *=0.001, * *=0.01$, and $*=0.05$. 
with $F$. verticillioides. Fertilizer (N-P-K, 60-30-30) was applied at a low rate to create plant stress and simulate conditions in African farm fields. Apron plus (Novartis Crop Protection, Basel, Switzerland) was applied to all seeds to prevent downy mildew infection.

Inoculation methods. The A. flavus isolate was obtained from a naturally infected ear found at the IITA station, Ibadan, Nigeria, and maintained on acidified potato dextrose agar (PDA) for the first inoculation (internal reference isolate number IITA MP00196.NAF). The fungus was reisolated from inoculated ears for growth on acidified PDA and used for inoculation during the second season (internal reference isolate number IITA MP00296.NAF). In both seasons, at 5 and 10 days past mid-silk, $2 \mathrm{ml}$ of an A. flavus conidial suspension $\left(1 \times 10^{6} / \mathrm{ml}\right)$ was atomized on the silk of all primary cobs in one row of each main plot $(27,47)$.

The $F$. verticillioides isolate was obtained from a naturally infected ear found in a farmer's field near Ibadan, Nigeria (internal reference isolate number IITA MP00196.NFM), and species identification was made by observing Fusarium spp. macro- and microconidia and single-filament microconidial chains when cultured on $\mathrm{KCl}$ (34). The fungus was reisolated from inoculated ears, cultured, and used for inoculation during in the second season (internal reference isolate number IITA MP00296.NFM). Inoculum was grown on acidified PDA, and microconidia were washed into a suspension with distilled water. At 10 and 15 days past mid-silk, $2 \mathrm{ml}$ of $F$. verticillioides inoculum $\left(1 \times 10^{6} / \mathrm{ml}\right)$ was atomized on the silks of all primary cobs in one row of each main plot (9).

The silks of different genotypes were inoculated with suspensions of A. flavus or $F$. verticillioides, and the controls were inoculated with water. All spray suspensions and water controls were amended with $1 \%$ (vol/vol) Triton X-100 to increase adhesion. All sprayings were carried out between 5:30 and 6:30 p.m. The sprayed cobs were covered for $24 \mathrm{~h}$ with a pollination bag to prevent rain or dew from dislodging the spores and to prevent cross-contamination. The control rows were sprayed first and covered to avoid contamination at each inoculation.

Ear and grain characteristics. A husk-cover rating was done per row on a scale of 1 to 5 just prior to harvest, as described by Kossou et al. (22), where $1=$ husk well extended beyond the ear tip and $5=$ ear tip exposed. From each row, five ears were set aside for laboratory analyses, and the rest of the ears were harvested and dehusked. An ear rot rating was done on the bulk of the harvested cobs on a scale of 1 to 5 , based on a visual assessment of grain color and development, where 1 = sound, unblemished kernels and $5=$ kernels damaged, covered with fungus, or discolored. An insect-damage rating on a scale of 1 to 5 also was made on the row, where $1=0$ to $5 \%, 2=6$ to $25 \%, 3=26$ to $50 \%$, $4=51$ to $75 \%$, and $5=76$ to $100 \%$ insect-damaged kernels (5). Moisture content was assessed with a Dickey John moisture tester.

Grain density, which is an indirect measure of the ratio of hard to soft endosperm texture, was determined by a flotation test (53). A sodium nitrate solution with specific gravity of 1.25 at ambient temperature was used to measure the percentage of floating kernels from 50 kernels in $500 \mathrm{ml}$ of solution. The specific gravity of the solution was checked with a hydrometer before, during, and after measurement. A Stenvert grain hardness test was conducted (37).

TABLE 3. Effects of season, maize genotype, cycle of selection, and inoculation treatment on fungal and insect variables

\begin{tabular}{|c|c|c|c|c|c|c|}
\hline Variable & $\begin{array}{c}\text { Aspergillus flavus }{ }^{\mathrm{a}} \\
(\%)\end{array}$ & $\begin{array}{c}\text { Fusarium verticillioides }^{\mathrm{a}} \\
(\%)\end{array}$ & $\begin{array}{l}\text { Other fungi }{ }^{\mathrm{a}} \\
\qquad \%)\end{array}$ & Insect damage $^{b}$ & No. of borers & No. of beetles \\
\hline \multicolumn{7}{|l|}{ ANOVA $^{c}$} \\
\hline Season & $* * *$ & $\mathrm{~ns}$ & $* *$ & $*$ & $* *$ & ns \\
\hline Genotype & ns & ns & ns & ns & ns & ns \\
\hline Season $\times$ genotype & ns & ns & ns & ns & ns & $*$ \\
\hline Cycle & ns & ns & ns & ns & ns & ns \\
\hline Treatment & $* * *$ & $* * *$ & $* * *$ & $* * *$ & $*$ & $* * *$ \\
\hline Treatment $\times$ season & $* * *$ & $* * *$ & $* * *$ & $* * *$ & ns & ns \\
\hline Treatment $\times$ genotype & $*$ & ns & ns & ns & ns & ns \\
\hline \multicolumn{7}{|c|}{ ANOVA by fungal treatment ${ }^{\mathrm{d}}$} \\
\hline \multicolumn{7}{|l|}{ Af treatment } \\
\hline Season & $* *$ & ns & ns & ns & $* *$ & ns \\
\hline Genotype & ns & ns & ns & ns & $*$ & ns \\
\hline Season $\times$ genotype & ns & ns & ns & $*$ & $*$ & ns \\
\hline Cycle & ns & ns & ns & ns & $* *$ & ns \\
\hline Cycle $\times$ season & ns & ns & ns & ns & $* *$ & ns \\
\hline \multicolumn{7}{|l|}{$\mathrm{C} 1$} \\
\hline Season & ns & ns & $*$ & $*$ & $* *$ & $*$ \\
\hline Genotype & $* *$ & $*$ & ns & ns & ns & ns \\
\hline Season $\times$ genotype & ns & ns & ns & ns & ns & ns \\
\hline Cycle & $\mathrm{ns}$ & ns & ns & ns & ns & ns \\
\hline Cycle $\times$ season & ns & ns & ns & ns & ns & $* *$ \\
\hline \multicolumn{7}{|l|}{$\mathrm{C} 2$} \\
\hline Season & $* * *$ & $* *$ & ns & ns & ns & ns \\
\hline Genotype & $* *$ & ns & ns & ns & ns & ns \\
\hline Season $\times$ genotype & $* * *$ & ns & ns & ns & ns & ns \\
\hline Cycle & ns & ns & ns & ns & ns & ns \\
\hline Cycle $\times$ season & ns & ns & ns & ns & ns & ns \\
\hline \multicolumn{7}{|l|}{ Fv treatment } \\
\hline Season & $* *$ & ns & ns & $*$ & $*$ & ns \\
\hline Genotype & ns & ns & ns & ns & ns & ns \\
\hline Season $\times$ genotype & ns & ns & ns & ns & ns & ns \\
\hline Cycle & ns & ns & ns & ns & ns & ns \\
\hline Cycle $\times$ season & ns & ns & ns & ns & ns & ns \\
\hline
\end{tabular}

a Percent kernel damage by fungi is arcsine square-root transformed.

b Visible ear damage on a 1 to 5 scale, where 1 is low and 5 is high.

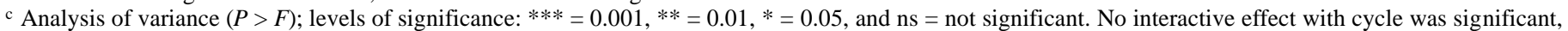
and no higher order interaction terms were significant.

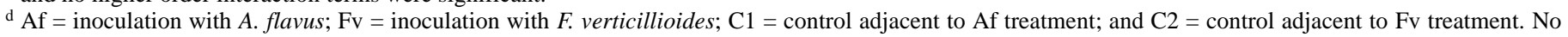
other interactions were significant. 
Insect counts. At harvest, five ears with husk were selected at random and removed from each row, placed in a cloth bag, and taken to the laboratory for insect counts. Each ear was dehusked separately, and lepidopterous borers were immediately identified to species and counted by species. Beetles were collected with an aspirator, pooled, and stored in a freezer for later counting. Numbers of beetles collected from five ears were analyzed as a pooled sample, and species were identified.

Fungal quantification. The five ears assessed for insect infestation were shelled by hand. Five kernels per ear were selected at random for a total of 25 kernels per sample. The kernels were surface-disinfected for $1 \mathrm{~min}$ in $3.5 \% \mathrm{NaOCl}$, rinsed in sterile distilled water, and plated on sterile filter paper. Plated kernels were incubated at $26^{\circ} \mathrm{C}$ and fungal species were assessed directly on the plates after 7 days. Only A. flavus and $F$. verticillioides were identified to species and recorded, while all other fungi were grouped and recorded as "other."

Mycotoxin analysis. The remainder of the kernels from the five ears were bulked and ground in a mill (Romer Labs Inc., Union, MO) and 50-g subsamples each were assayed for aflatoxin and fumonisin. Parts per billion of aflatoxin B1 and B2 were assessed by extraction and thin-layer chromatography for quantification (46). Sensitivity ranged from 3 to $500 \mathrm{ppb}$ for this analysis. For fumonisin analysis, a fumonisin Veratox kit (Neogen Corp., Lansing, MI) was used, and optical density was scanned with a microplate reader (MR250; Dynatech Laboratories, Chantilly, VA) with a $650-\mathrm{nm}$ absorbency filter. This assay was sensitive to $0.5 \mathrm{ppm}$.
Due to logistics, aflatoxin analyses were performed only on the $A$. flavus-inoculated row and its control, and fumonisin analysis was performed only on the $F$. verticillioides row and its control.

Grain-loss assessment. The weight of a 100-grain sample (subsampled from five ears) was taken in the laboratory. Grains damaged by insects and those discolored by fungi were sorted out of the 100 grains, leaving the consumable grain, which was weighed. The percentage of loss due to biotic factors was calculated as the difference between the total 100-grain weight and the consumable-grain weight (7).

Data analysis. Data was analyzed with a Statistical Analysis Systems program (version 6.12, SAS Institute, Cary, NC). A mixedmodel analysis of variance (ANOVA) was used to test the random effect replicate (season) and the fixed effects of season, genotype, cycle of selection, and inoculation treatments on ear- and grainquality parameters (25). A multivariate ANOVA procedure was run but did not provide further information. A correlation analysis of the relationships among the ear rot pathogens, insects, and ear and grain parameters by row was performed using season A data only. Percent fungal kernel infection data were arcsine square-root transformed prior to analysis. Untransformed means are shown in figures and tables.

\section{RESULTS}

Seasonal factors. Averages of ear- and grain-quality variables for each season and mean differences among treatments are shown

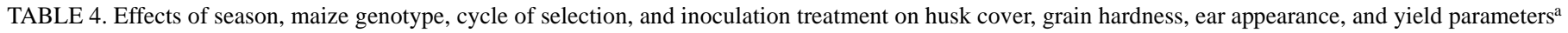

\begin{tabular}{|c|c|c|c|c|c|c|}
\hline Parameter & $\begin{array}{l}\text { Husk cover }^{\mathrm{b}} \\
\qquad(P>F)\end{array}$ & $\begin{array}{l}\text { Floaters }(\%) \\
\quad(P>F)\end{array}$ & $\begin{array}{l}\text { 100-grain wt (g) } \\
(P>F)\end{array}$ & $\begin{array}{c}\text { Consumable-grain } \mathrm{wt}^{\mathrm{c}} \\
\qquad(P>F)\end{array}$ & $\begin{array}{l}\text { Field wt } \\
(P>t)\end{array}$ & $\begin{array}{c}\text { Ear rot }^{\mathrm{d}} \\
(P>t)\end{array}$ \\
\hline \multicolumn{7}{|l|}{ ANOVA } \\
\hline Season & $\mathrm{ns}$ & $*$ & ns & $*$ & ns & $*$ \\
\hline Genotype & $* * *$ & $* * *$ & $*$ & $\mathrm{~ns}$ & $*$ & ns \\
\hline Season $\times$ genotype & ns & $* * *$ & ns & ns & ns & ns \\
\hline Cycle & $* *$ & $* *$ & $*$ & ns & $* *$ & ns \\
\hline Cycle $\times$ season & ns & $* *$ & ns & ns & ns & ns \\
\hline Cycle $\times$ genotype & ns & $* *$ & ns & ns & ns & ns \\
\hline Treatment & $* * *$ & $*$ & ns & $* * *$ & $* * *$ & $* * *$ \\
\hline Season $\times$ treatment & ns & ns & ns & ns & $*$ & $* * *$ \\
\hline Genotype $\times$ treatment & ns & ns & ns & ns & ns & $*$ \\
\hline \multicolumn{7}{|c|}{ ANOVA by fungal treatement ${ }^{\mathrm{e}}$} \\
\hline \multicolumn{7}{|l|}{ Af treatment } \\
\hline Season & ns & ns & ns & $*$ & $*$ & $* *$ \\
\hline Genotype & $* *$ & $* *$ & ns & $\mathrm{ns}$ & $*$ & ns \\
\hline Season $\times$ genotype & ns & ns & ns & ns & ns & ns \\
\hline Cycle & $*$ & ns & ns & $\mathrm{ns}$ & ns & ns \\
\hline \multicolumn{7}{|l|}{$\mathrm{C} 1$} \\
\hline Season & ns & ns & ns & ns & ns & ns \\
\hline Genotype & $* *$ & ns & $* *$ & $*$ & ns & $*$ \\
\hline Season $\times$ genotype & ns & ns & ns & ns & ns & ns \\
\hline Cycle & $\mathrm{ns}$ & ns & $*$ & ns & ns & ns \\
\hline Cycle $\times$ genotype & ns & ns & $*$ & ns & ns & ns \\
\hline \multicolumn{7}{|l|}{$\mathrm{C} 2$} \\
\hline Season & ns & ns & $*$ & ns & ns & ns \\
\hline Genotype & $* * *$ & $*$ & ns & ns & ns & ns \\
\hline Season $\times$ genotype & ns & $*$ & ns & ns & ns & ns \\
\hline Cycle & $* *$ & $*$ & ns & ns & ns & ns \\
\hline Cycle $\times$ season & $\mathrm{ns}$ & $*$ & ns & ns & ns & ns \\
\hline \multicolumn{7}{|l|}{ Fv treatment } \\
\hline Season & ns & ns & $*$ & $\mathrm{~ns}$ & ns & ns \\
\hline Genotype & $* *$ & $*$ & ns & ns & ns & ns \\
\hline Season $\times$ genotype & ns & $* *$ & ns & ns & ns & ns \\
\hline Cycle & $*$ & $* *$ & ns & ns & $*$ & ns \\
\hline Cycle $\times$ season & ns & $* *$ & ns & ns & ns & ns \\
\hline
\end{tabular}

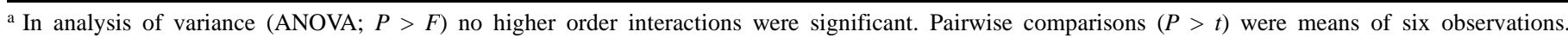
Interactions with cycle not shown were not significant. Levels of significance: $* * *=0.001, * *=0.01, *=0.05$, and ns $=$ not significant.

${ }^{\mathrm{b}}$ Husk cover rating ( 1 to 5 scale, where $1=$ husk well extended beyond the ear tip and $5=$ ear tip exposed).

c Weight per 100 kernels.

${ }^{\mathrm{d}}$ Ear rot rating ( 1 to 5 scale, where $1=$ sound and $5=$ damaged).

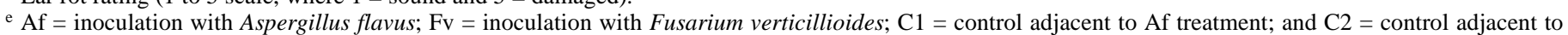
Fv treatment. 
in Table 2. ANOVA for the variables are shown in Tables 3 and 4. In the general ANOVA, there was a significant seasonal effect on percentage of A. flavus and other fungi in kernels, ear damage rating, number of ear borers, percent floaters, grain hardness, and ear rot ratings (Tables 3 and 4). The percentage of kernels infected with $A$. flavus dropped from a mean infection of $77.4 \%$ in the $A$. flavus-inoculated plots in season A to $35.2 \%$ in season B, although this was not significant (Fig. 1). In the Fusarium spp.-inoculated rows, $F$. verticillioides infection was $71.4 \%$ in season $\mathrm{A}$ and $74.4 \%$ in season B (Table 2). Percentages of other fungi were significantly higher in the control rows in the first compared with the second season. There was no seasonal effect detected in the ear damage ratings (scale of 1 to 5 ) or beetle numbers (Table 3 ). Ear borer numbers declined significantly from the highest mean (in the $F$. verticillioides inoculation) of 7.8 borers per 5 ears in the A season to less than 1 borer per 5 ears in season B. In contrast, beetle numbers increased in the $F$. verticillioides-inoculated rows from 27.4 to 33.4 beetles per 5 ears. Husk-cover ratings were not affected by season, while grain density (percent floaters) did change significantly (Table 4).

Aflatoxin (parts per billion of B1 + B2) in the A. flavus-inoculated rows increased from $327 \mathrm{ppb}$ in the first season to $589 \mathrm{ppb}$ in
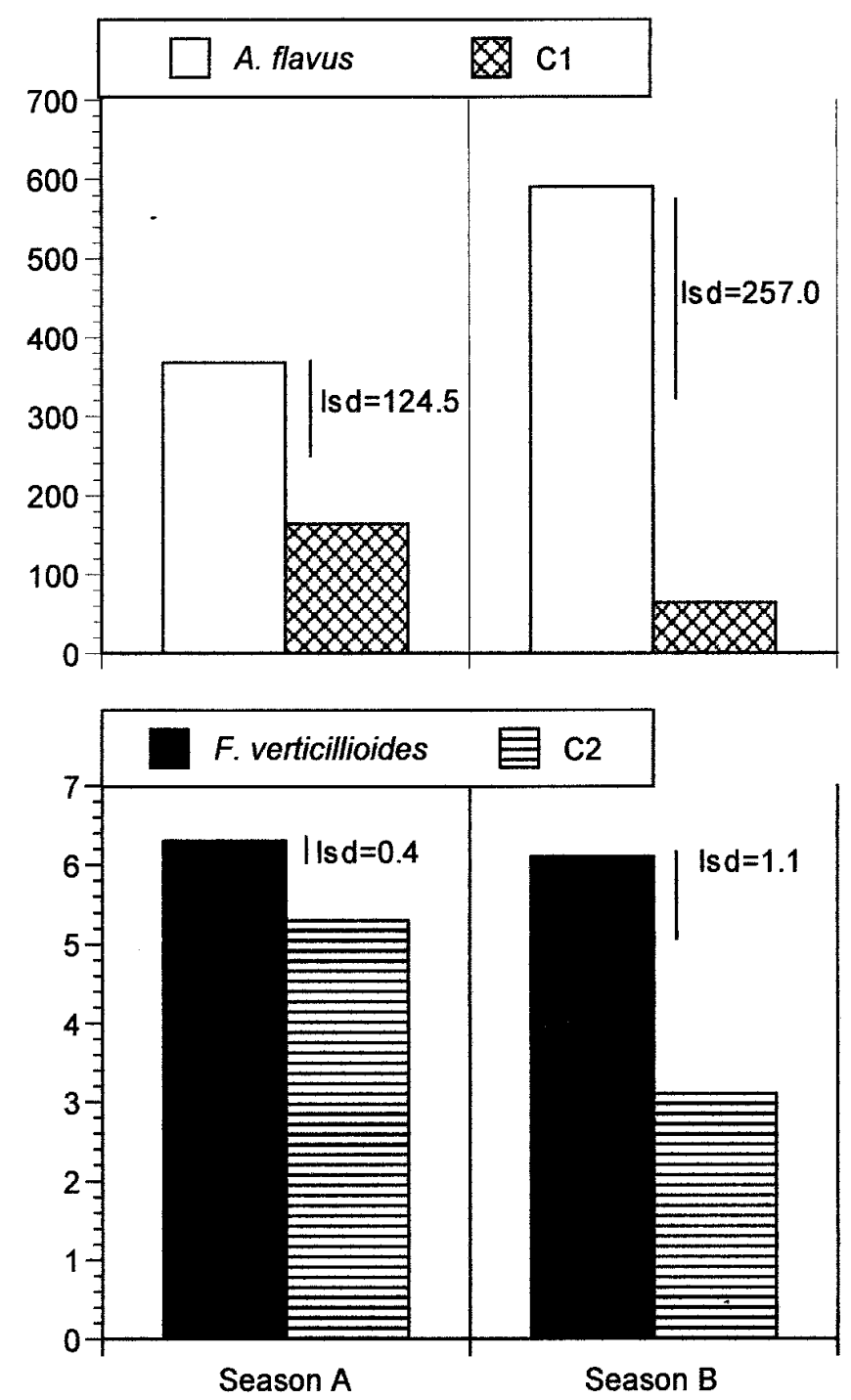

Fig. 1. Effect of season and inoculation with Aspergillus flavus on parts per billion of aflatoxin (B1 and B2) production relative to the noninoculated control (C1) and inoculation with Fusarium verticillioides on parts per million of fumonisin production relative to the noninoculated control $(\mathrm{C} 2)$. Season least significant difference (LSD) for aflatoxin $=143$ and for fumonisin $=0.7$. the second (Fig. 1), although the difference was not significant. In the $F$. verticillioides-inoculated rows, fumonisin levels were not significantly different between seasons, with 6.3 and $6.1 \mathrm{ppm}$ in the first and second seasons, respectively. However, in the noninoculated control rows, fumonisin differences between seasons were significant, with $5.3 \mathrm{ppm}$ fumonisin in the first season and $3.1 \mathrm{ppm}$ in the second (Fig. 1).

Genotype effects. Maize genotype did not have a significant effect on toxin production or fungal or insect-related pest variables (Table 3), but grain and ear characteristics were significantly different among genotypes (Table 4).

Fungal treatments. The inoculation treatments were highly effective as indicated by significant treatment effects (Tables 2 and 3 ). The mean infection levels by $A$. flavus and $F$. verticillioides were inversely related in the respective treatments (Table 2). The noninoculated controls showed some signs of contagion by the inoculated neighbor. Control 1 (C1), which was adjacent to the $A$. flavus-inoculated plot, had a higher percentage of kernels infected with A. flavus than either control 2 (C2) or the F. verticillioides treatment. $\mathrm{C} 2$ had significantly more $F$. verticillioides than $\mathrm{C} 1$ or the A. flavus treatment (Table 2).

There was a significant interaction between genotype and inoculation treatment for percentage of A. flavus. Significant differences in A. flavus incidence among maize genotypes could only be seen in the ANOVA by fungal inoculation treatment (Table 3 ). There
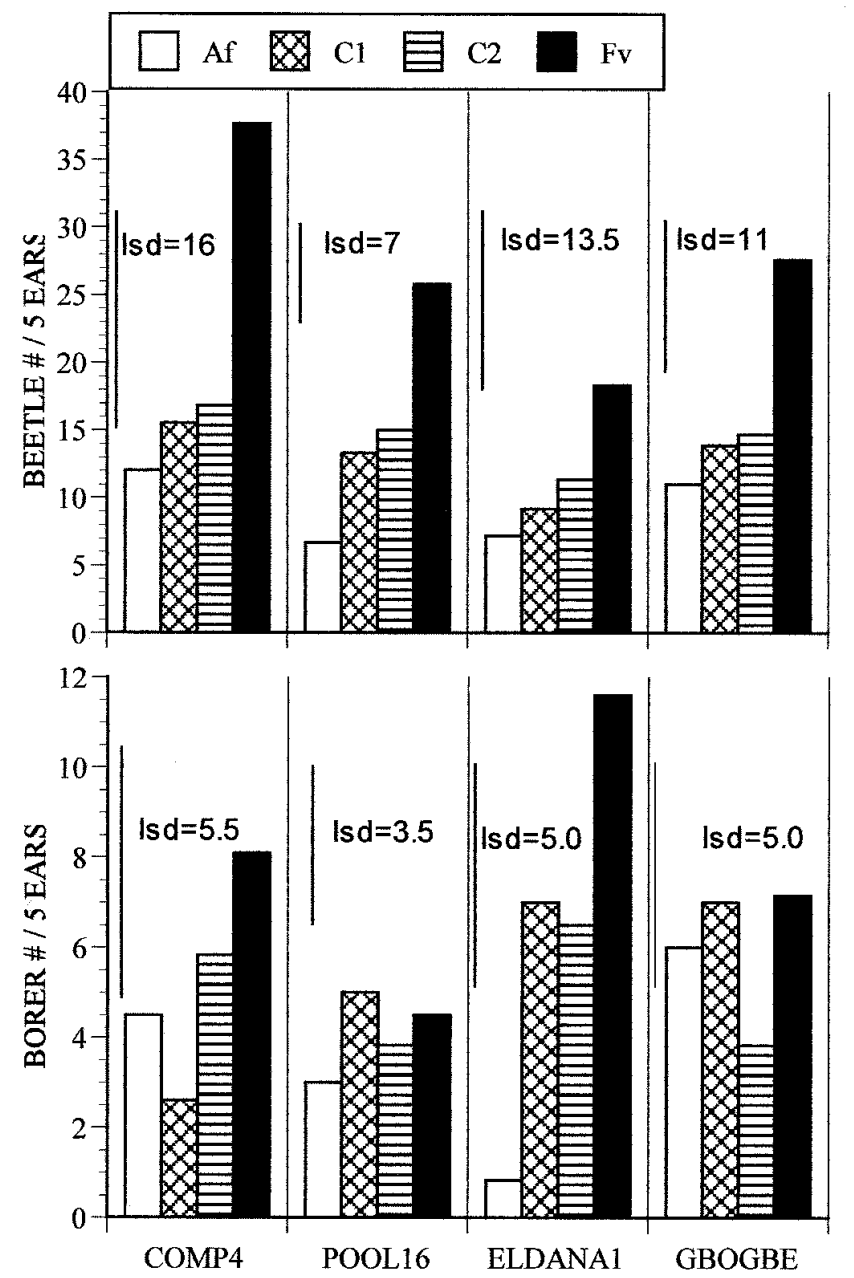

Fig. 2. Effect of inoculations with Aspergillus flavus (Af) and Fusarium verticillioides $(\mathrm{Fv})$, and controls with no fungal inoculations $(\mathrm{C} 1$ and $\mathrm{C} 2$, respectively) on the number of beetles and ear borers per five ears in four maize genotypes. Insect numbers are means of six observations in season A. Least significant difference (LSD) across genotypes for beetles $=6.4$ and for borers $=2.9$. 
were consistent differences in both seasons for A. flavus infection among genotypes in the control treatments (Table 3 ). The least significant mean (LSM) genotype infection with A. flavus in the C1 treatment across seasons was Eldana 1, 32\% > Gbogbe, $23 \%>$ composite 4, 22\% > Pool 16, 21\% ( $P>t$ for Eldana 1 versus composite $4=0.006$, and for Eldana 1 versus Pool $16=0.002)$. This genotype ranking did not change between seasons. Although differences among genotypes for percentage of $F$ verticillioides were generally not significant, Eldana 1 also had significantly more of this fungus than the other genotypes in the $\mathrm{C} 1$ treatment.

Insect variables. The four species of ear borers encountered, listed in descending order of frequency, were M. nigrivenella, $E$. saccharina, Sesamia calamistis, and Cryptophlebia leucotreta Meyrick (Tortricidae). Beetles listed in descending order of frequency were Sitophilus zeamais, Cathartus quadricollis, a Carpophilus sp.,
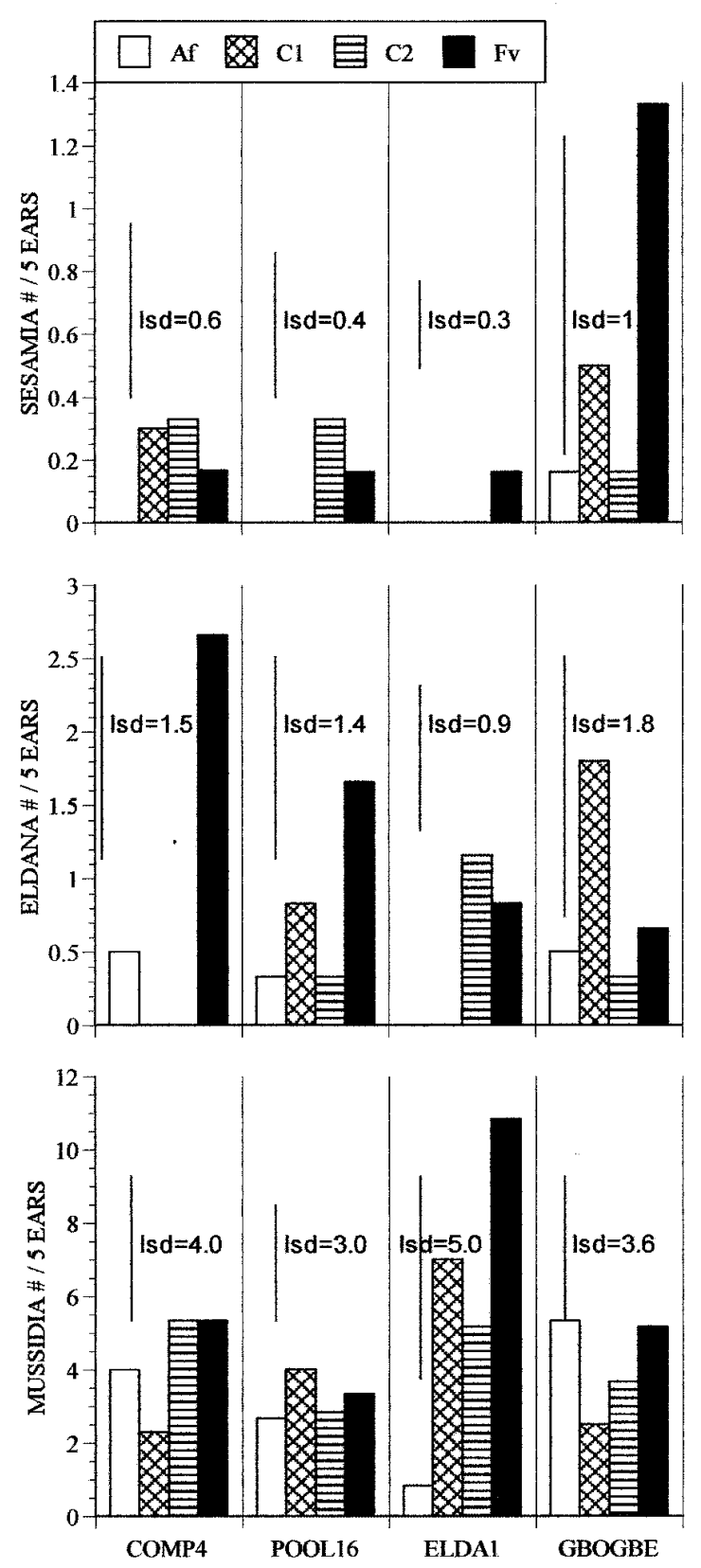

Fig. 3. Effect of inoculations with Aspergillus flavus (Af) and Fusarium verticillioides $(\mathrm{Fv})$, and controls with no fungal inoculations $(\mathrm{C} 1$ and $\mathrm{C} 2$, respectively) on the number of ear borers per five ears of four maize genotypes in season A: Sesamia calamistis, least significant difference (LSD) across genotypes $=0.5 ;$ Eldana saccharina, $\mathrm{LSD}=1.1 ;$ and Mussidia nigrivenella, $\mathrm{LSD}=$ 2.8. Borer numbers are means of six observations.
Tribolium castaneum (Tenebrionidae), a Palorus sp. (Tenebrionidae), and a Cryptolestes sp. (Laemophloeidae).

In the general ANOVA, season and fungal inoculation had a significant effect on the rating of ear damage by insects, counts of borers, and number of beetles per five ears (Table 3). The pairwise differences in the LSM of the insect variables showed that the $F$. verticillioides inoculation resulted in significantly higher insect damage ratings and beetle numbers than either the controls or the A. flavus treatment (Table 2).

In the ANOVA by A. flavus treatment, maize genotypes were significantly different in the number of borers per five ears in the A. flavus treatment (Table 3). This effect occurred in season A, when borer pressure was highest and was not seen in the other inoculation treatments. In the rows where A. flavus was introduced into the ears, the borer-resistant genotype Eldana 1 had significantly lower borer numbers than the other genotypes (Fig. 2).

To better understand the relationship between borers and the fungal inoculations, the borer counts were separated by species (Fig. 3). Eldana 1 had Sesamia calamistis only in the F. verticillioides-inoculated ears and E. saccharina only in the F. verticillioides-inoculated and neighboring control (C2) rows. Gbogbe had significantly more $S$. calamistis than the other genotypes, particularly when inoculated with $F$. verticillioides. Composite 4 had significantly more $E$. saccharina in the $F$. verticillioides treatment than in the other inoculation treatments. The genotype Eldana 1 had significantly more $M$. nigrivenella in the $F$. verticillioidesinoculated row and significantly less in the A. flavus-inoculated row. The other genotypes had no apparent fungus by Mussidia interaction.

Ear and grain characteristics. There were significant genotype and cycle-of-selection reactions for all of the ear and grain characteristics except consumable-grain weight and the ear-rot rating (Table 4). In both seasons, the rows inoculated with either fungus had a higher rating for husk extension (poorer husk cover and decreased extension) than the controls (Table 2, Fig. 4). Percent kernel flotation as an inverse measure of grain density was inherently different among genotypes. In advanced cycles of selection, percent flotation was reduced although, with fungal inoculation, the percentage increased. Weight (100 grain) was significantly different among genotypes and increased significantly with cycle of

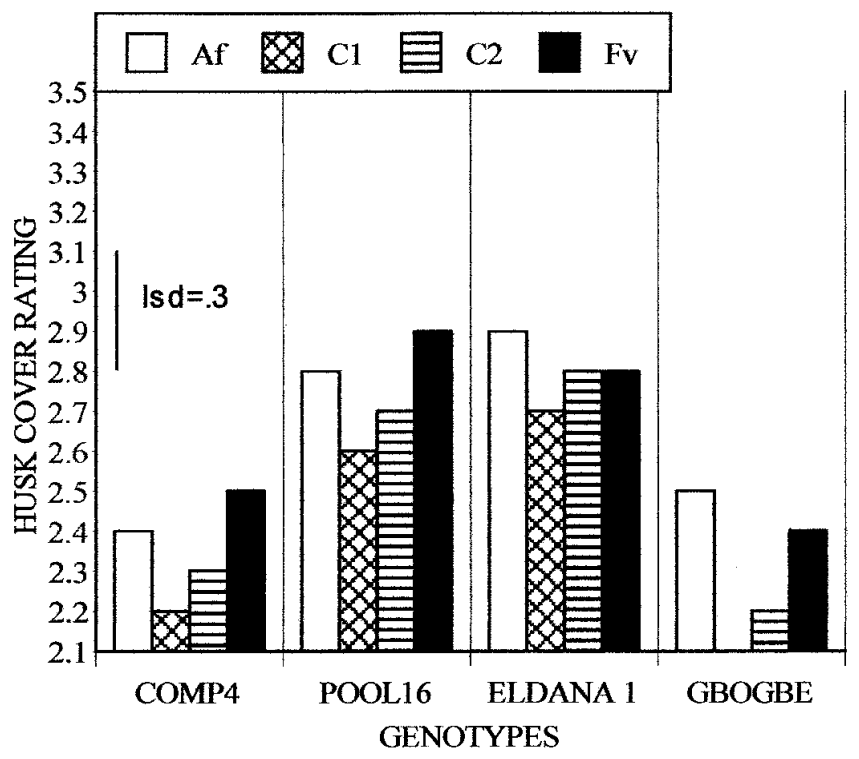

Fig. 4. Effect of inoculations with Aspergillus flavus (Af) and Fusarium verticillioides $(\mathrm{Fv})$, and controls with no fungal inoculations $(\mathrm{C} 1$ and $\mathrm{C} 2$, respectively) on husk cover extension rating $(1=\operatorname{good}$ and $5=$ poor $)$ in four maize genotypes. Least significant difference (LSD) across genotypes $=0.13$; bars show means of 12 ratings. 
selection, although consumable-grain weight of 100 grains did not change with cycles of selection. Consumable-grain weight was significantly affected by inoculation treatments. This was linked to ear rot ratings, which also were not affected by genotype or improved with cycle of selection (Tables 2 and 4). The advanced cycle of all genotypes had significantly better field weight (kilograms per hectare), but fungal inoculation decreased yield significantly.

Mycotoxins. Within both seasons, aflatoxin contamination in the A. flavus inoculated ears was significantly higher $(P \geq F=0.0001)$ than in the controls (C1) but was not significantly different between cycles of selection or among genotypes in either the first or second season (Fig. 1). The trend, however was that Pool 16 consistently had the lowest mean aflatoxin levels in the inoculated rows, with $354 \mathrm{ppb}$, compared with $533 \mathrm{ppb}$ in composite 4. Likewise, within both seasons, the $F$. verticillioides-inoculated row had significantly higher levels of fumonisin than the control (C2). Again, the trend was that Pool 16 had the lowest mean fumonisin level across seasons, with 5.5 ppm, compared with the highest contamination level, $6.6 \mathrm{ppm}$, in Gbogbe.

Correlations. The negative correlation between percent incidence of A. flavus and F. verticillioides in kernels was highly significant (Table 5) but mostly an effect of experimental design. Significant negative correlations occurred between A. flavus and all insect variables: number of kernels damaged per 100 kernels, ear damage, and numbers of borers and beetles. The presence of $F$. verticillioides in the ear was negatively correlated with all other fungi but significantly positively correlated with all insect and damage variables. Both the ear damage rating ( 1 to 5 scale used by entomologists) and the ear rot rating (1 to 5 scale used by breeders) were positively related to $F$. verticillioides, grain-weight loss, and insect counts. Counts of discolored grain at harvest were significantly negatively correlated with other fungi, but this was probably an artifact of experimental design, because other fungi were present primarily in the control rows in much lower incidence than $F$. verticillioides. Count of insect-damaged grain at harvest was correlated with discolored grain and autocorrelated with grain-weight loss (damage was a criterion for sorting out consumable grain). Beetle and borer numbers were correlated with each other and with damage counts, while only beetle numbers were correlated to grain discoloration. Grain-weight loss was correlated with the two damage-rating scales, beetle counts, and F. verticillioides incidence. Borers were positively related with damagedkernel counts, beetles and ear damage rating. Beetles were positively correlated with $F$. verticillioides and all other damage measurements. The husk-cover rating correlated negatively with field weight but was positively correlated with percent floaters, indicating that husk cover and grain hardness increased with yield. There were significant negative correlations between field weight and grainweight loss, ear rot rating, and percent floaters. Grain density (the inverse of percent floaters) was negatively correlated with insect ear-damage rating and increased with field weight. Grain hardness and percent floaters were inversely related, and grain hardness was positively correlated with percent discoloration of grain and grainweight loss.

\section{DISCUSSION}

Fungal interactions. Silk inoculation was consistently successful, because high levels of infection were obtained in both seasons. The control rows were used to determine genotypic response under more moderate inoculum pressure, as well as to assess the effects of fungal infection in the inoculated rows. The ear rot ratings ( 1 to 5 scale used by breeders) and ear damage ratings (used by entomologists) were good predictors of levels of $F$. verticillioides, the general category of other fungi, and insects at harvest; however, they were not good indicators for A. flavus.

Fungus-insect interactions. In this study, mean numbers of both beetles and borers tended to be lower in A. flavus-treated rows. The relationship between insects and A. flavus is not necessarily straightforward. Insects have vectored A. flavus $(3,50)$, and a strong relationship between insect feeding in the ear and aflatoxin contamination has been demonstrated $(3,24,41,42)$. Conversely, the larvae of Chilo partellus (Pyralidae) were killed and mummified by A. flavus (2). A reduction in the survival rate of Heliothis zea and Spodoptera frugiperda (Noctuidae) was observed when reared on a diet treated with spores of A. flavus and A. parasiticus (52). On the other hand, $M$. nigrivenella was not sensitive to aflatoxin or A. flavus in the diet (52). F. verticillioides, likewise, may be introduced into the stem and ear via insects $(21,29,31)$, although the cause and effect relationship is not clear. In this research, numbers of borers and beetles in the ear at harvest were significantly higher in the $F$. verticillioides-inoculated rows (Fig. 2).

$F$. verticillioides has been variously described as an entomopathogen and as an insect-growth promoter $(1,14,38,45)$. It has been identified as an entomopathogen of Heliothis virescens (1), on forest pests (38) and on the rice brown planthopper (45) and has been described as a growth promoter of storage coleopteran infestation of cereals (14). It is unclear in this experiment if the higher numbers of insects were due to an attraction to the inoculated cobs or simply higher survival rates. Subsequent experiments have shown significantly higher survivorship rates of $E$. saccharina in $F$. verticillioides-infected maize stems than in noninfected stems (K. F. Cardwell and F. Schulthess, unpublished data), but all of the interactions have not been explored.

TABLE 5. Correlations among fungus, insect, and ear and grain characteristics in season A $(n=96 \text { rows })^{\mathrm{a}}$

\begin{tabular}{|c|c|c|c|c|c|c|c|c|c|c|c|c|c|c|}
\hline & 1 & 2 & 3 & 4 & 5 & 6 & 7 & 8 & 9 & 10 & 11 & 12 & 13 & 14 \\
\hline 1 & 1.00 & $\ldots$ & $\ldots$ & $\ldots$ & $\ldots$ & $\ldots$ & $\ldots$ & $\ldots$ & $\ldots$ & $\ldots$ & $\ldots$ & $\ldots$ & $\ldots$ & $\ldots$ \\
\hline 2 & $-0.66 * * *$ & 1.00 & $\ldots$ & $\ldots$ & $\ldots$ & $\ldots$ & $\ldots$ & $\ldots$ & $\ldots$ & $\ldots$ & $\ldots$ & $\ldots$ & $\ldots$ & $\ldots$ \\
\hline 3 & -0.19 & $-0.30 * *$ & 1.00 & $\ldots$ & $\ldots$ & $\ldots$ & $\ldots$ & $\ldots$ & $\ldots$ & $\ldots$ & $\ldots$ & $\ldots$ & $\ldots$ & $\ldots$ \\
\hline 4 & 0.15 & $0.41 * * *$ & $-0.34 * * *$ & 1.00 & $\ldots$ & $\ldots$ & $\ldots$ & $\ldots$ & $\ldots$ & $\ldots$ & $\ldots$ & $\ldots$ & $\ldots$ & $\ldots$ \\
\hline 5 & $-0.25 *$ & $0.56^{* * * *}$ & -0.13 & $0.43^{* * *} *$ & 1.00 & $\ldots$ & $\ldots$ & $\ldots$ & $\ldots$ & $\ldots$ & $\ldots$ & $\ldots$ & $\ldots$ & $\ldots$ \\
\hline 6 & 0.04 & $0.45 * * *$ & $-0.34 * * *$ & $0.81 * * *$ & $0.54 * * *$ & 1.00 & $\ldots$ & $\ldots$ & $\ldots$ & $\ldots$ & $\ldots$ & $\ldots$ & $\ldots$ & $\ldots$ \\
\hline 7 & $-0.26^{*}$ & $0.54 * * *$ & -0.13 & $0.35^{* * *} *$ & $0.67 * * *$ & $0.47 * * *$ & 1.00 & $\ldots$ & $\ldots$ & $\ldots$ & $\ldots$ & $\ldots$ & $\ldots$ & $\ldots$ \\
\hline 8 & $-0.21 *$ & $0.31 * *$ & -0.12 & 0.08 & $0.38 * * *$ & 0.24 & $0.53 * * *$ & 1.00 & $\ldots$ & $\ldots$ & $\ldots$ & $\ldots$ & $\ldots$ & $\ldots$ \\
\hline 9 & $-0.33 * *$ & $0.49 * * *$ & -0.10 & $0.28 * *$ & $0.50 * * *$ & $0.28 * *$ & $0.45 * * *$ & $0.22 *$ & 1.00 & $\ldots$ & $\ldots$ & $\ldots$ & $\ldots$ & $\ldots$ \\
\hline 10 & 0.04 & 0.16 & -0.10 & 0.10 & 0.07 & 0.10 & 0.14 & 0.17 & 0.01 & 1.00 & $\ldots$ & $\ldots$ & $\ldots$ & $\ldots$ \\
\hline 11 & 0.04 & -0.17 & 0.05 & -0.10 & -0.15 & -0.24 & -0.19 & -0.15 & -0.20 & $-0.26^{*}$ & 1.00 & $\ldots$ & $\ldots$ & $\ldots$ \\
\hline 12 & -0.06 & $0.45^{* * * *}$ & $0.37 * * *$ & $0.36^{* * *} *$ & $0.36 * * *$ & $0.46^{* * *} *$ & $0.36^{* * *} *$ & 0.19 & $0.26^{*}$ & 0.18 & $-0.31 * *$ & 1.00 & $\ldots$ & $\ldots$ \\
\hline 13 & -0.02 & 0.19 & -0.16 & 0.13 & 0.09 & 0.19 & $0.22 *$ & 0.18 & -0.06 & $0.39 * * *$ & $-0.44 * * *$ & $0.32 * *$ & 1.00 & $\ldots$ \\
\hline 14 & 0.01 & 0.15 & -0.12 & $0.33^{* * *} *$ & -0.15 & $0.27 * *$ & 0.07 & -0.02 & 0.07 & 0.05 & -0.03 & 0.15 & $-0.28 * *$ & 1.00 \\
\hline
\end{tabular}

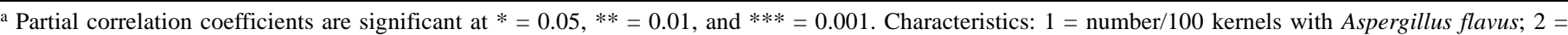
number/100 kernels with Fusarium verticillioides; $3=$ number/100 kernels with other fungi; $4=$ number/100 kernels discolored at harvest; $5=$ number/100 kernels damaged by insects at harvest; $6=$ grain weight loss $[1-($ total 100 -grain wt - damaged grain wt/total 100 -grain wt $) \times 100]$; $7=$ ear insect damage $(1$ to 5 scale, where 1 is low and 5 is high); $8=$ number of borers/five ears; $9=$ number of beetles/five ears; $10=$ husk cover rating $(1$ to 5 scale, where $1=$ good and $5=$ poor $) ; 11=$ field weight $(\mathrm{kg} / \mathrm{ha}) ; 12=$ ear rot $(1$ to 5 scale, where $1=$ sound and $5=$ damaged $) ; 13=$ percent floaters; and $14=$ grain hardness. 
Fungus-insect-cultivar interactions. The presence of $F$. verticillioides had different effects on the various borers, depending on the host genotype (Fig. 3). The stem borer-resistant population Eldana 1 showed low numbers of both E. saccharina and Sesamia calamistis in our trials, and neither ear borer was present in ears inoculated with A. flavus or its adjacent control. This maize population was formed from lines known to exhibit resistance to multiple stem- and ear-boring insects $(6,43)$ and has been selected in the presence of both E. saccharina and S. calamistis over the years. Nevertheless, in the presence of $F$. verticillioides, the numbers of these borers were higher and the population became significantly more vulnerable to $M$. nigrivenella. In Eldana $1, A$. flavus reduced $M$. nigrivenella numbers significantly. This is in contrast with other findings that $M$. nigrivenella was not sensitive to A. flavus in vitro and that it increased with increasing $A$. flavus and aflatoxin in the field (42). In this experiment, the high dose of fungal inoculum may have overcome the tolerance.

Gbogbe $\times$ TZSR-W-1 is a population developed from a Benin local cultivar that has been shown to have good storability, with low beetle infestation (22), at least in part because of good husk cover (29). In the presence of $F$. verticillioides, it had a significantly reduced husk cover and more beetles than in the other treatment rows. This strong response could be responsible for some of the controversy over the inherent storability of this cultivar. In one study, Gbogbe was significantly more resistant to Sitophilus zeamais (22) while in another (29) no differences were seen between this cultivar and others.

The number of beetles was always highest in the $F$. verticillioidesinfected rows, regardless of genotype. The interactions we describe were not considered in past stem-borer or beetle-resistance breeding programs. If the level of susceptibility to these two fungi are different, or the fungi are a hidden environmental effect of location, it may be difficult to make progress in breeding for insect resistance or determine the cause of the observed variability.

Interaction of fungi and insects with ear and grain characteristics. Maize kernels differ in the amount of void space within the endosperm in relation to the starch/protein ratio, so floury endosperm has less protein content than flinty endosperm (33). With cycles of selection, we saw significant increases in 100-grain weight and in grain density. There was a loss of density in the presence of fungi, which was not unexpected, because fungal metabolism within maize kernels decreases dry-matter content and, thus, kernel density (40).

An exposed cob is more vulnerable than one enclosed in the husk, and good husk cover is considered key to protecting the ear from fungi and insects $(32,49,51)$. Yet, in this trial, husk rating correlated only with percent floaters and not with other damage scores. The husk extension was negatively correlated with field weight, showing that healthy ears were more likely to have long husks. Husk extension in the inoculated rows was decreased compared with the controls; thus, when selecting for good husk cover, it is necessary to be aware of possible genotype-fungus interactions. How the fungal inoculations resulted in reduced husk cover is unclear, but the effect was significant in the two genotypes with the best husk cover, composite 4 and Gbogbe. The phenomenon could be an artifact of the experimental design if a high dose of fungus in the ear at an early stage could compete for resources needed for development.

The efficacy of field evaluation methods for selection of better ears. The 1 to 5 ear-damage rating scale was a good indicator of both insect damage and $F$. verticillioides infection. The 1 to 5 ear rot score was as effective as the insect damage score, and it also was a predictor of field-weight loss; however, the ear rot and insect damage scores did not reflect A. flavus in the ear. Cycles of selection had improved yield, husk-cover rating, and grain density. With improved husk cover and harder grain, it would be expected to have improved resistance to ear and grain biota. Nevertheless, in these trials, we found no improvements in these characteristics with the cycle of selection. It is possible that, after a certain level of improvement in husk cover, the benefits in terms of protection of the ear do not continue to improve. Grain density when the grain is still filling may not be as important as the postharvest driedkernel density for discouraging invasion. Therefore, two important points are derived from this experiment: (i) passive selection for generally improved ear appearance, husk cover, and grain hardness and density is not a guarantee that the ear will be of good quality and storability after many cycles of selection; and (ii) when working on maize resistance to stem and ear borer, postharvest beetle, and milling characteristics, the presence of fungi, particularly $F$. verticillioides, in the plant will affect the variability of the system.

\section{ACKNOWLEDGMENTS}

We thank O. Ayinde, O. Ibikunle, and S. Odubiyi for excellent field and laboratory assistance; M. Koube and J. Houtegni for toxin and fungal analyses; S. Nokoe and B. Adegoke for SAS analyses; and F. Schulthess and an anonymous reviewer for critical review.

\section{LITERATURE CITED}

1. Abbas, H. K., and Mulrooney, J. E. 1994. Effect of some phytopathogenic fungi and their metabolites on growth of Heliothis virescens $(\mathrm{F}$.) and its host plants. Biocontrol Sci. Technol. 4:77-87.

2. Atwal, A. S., Singh, B., and Batta, G. S. 1973. Chilo partellus (Swinhoe): A new host of Aspergillus flavus Link and Fusarium sp. Curr. Sci. 42:582-586.

3. Beti, J. A., Phillips T. W., and Smalley, E. B. 1995. Effects of maize weevils (Coleoptera: Curculionidae) on production of aflatoxin B1 by Aspergillus flavus in stored corn. J. Econ. Entomol. 88:1776-1782.

4. Bosque-Pérez, N. A., and Mareck, J. H. 1990. Distribution and species composition of lepidopterous maize borers in southern Nigeria. Bull. Entomol. Res. 80:363-368.

5. Bosque-Pérez, N. A., and Mareck, J. H. 1991. Effect of the stem borer Eldana saccharina (Lepidoptera: Pyralidae) on the yield of maize. Bull. Entomol. Res. 81:243-247.

6. Bosque-Pérez, N. A., Mareck, J. H., Dabrowski, Z. T., Everett, L., Kim, S. K., and Efron, Y. 1989. Screening and breeding for resistance to Sesamia calamistis and Eldana saccharina. Pages 163-169 in: Toward Insect Resistant Maize for the Third World. Proc. Int. Symp. Methodol. Develop. Host Plant Resistance to Maize Insects. CIMMYT, Mexico, D.F.

7. Boxall, R. A. 1986. A Critical Review of the Methodology for Assessing Farm-Level Grain Losses After Harvest. Tropical Development and Research Institute, U.K.

8. Darrah, L. L., and Zuber, M. S. 1987. Yield and the genetic control of Aflatoxin in maize. Pages 236-246 in: Aflatoxins in Maize: Proceedings of the Workshop. M. S. Zuber, E. B. Lillihoj, and B. L. Renfro, eds. CIMMYT, Mexico, D.F.

9. Drepper, W. J., and Renfro, B. L. 1990. Comparison of methods for inoculation of ears and stalks of maize with Fusarium moniliforme. Plant Dis. 74:952-956.

10. Flett, B. C., and van Rensburg, J. B. J. 1992. Effect of Busseola fusca on the incidence of maize ear rot caused by Fusarium moniliforme and Stenocarpella maydis. S. Afr. J. Plant Soil 9:177-179.

11. Hell, K., Cardwell, K. F., Sétamou, M., and Poehling, H.-M. The influence of storage practices on aflatoxin contamination in maize in four agroecological zones of Bénin, West Africa. J. Stored Prod. Res. In press.

12. Hell, K., Udoh, J., Sétamou, M., Cardwell, K. F., and Visconti, A. 1996. Fungal infections and mycotoxins in maize in different agro-ecological zones of Benin and Nigeria, West Africa. Page 31 in: Proceedings of the Workshop Mycotoxins Foods Afr. K. F. Cardwell, ed. IITA, Cotonou, Benin.

13. Hoenisch, R. W., and Davis, R. M. 1994. Relationship between kernel pericarp thickness and susceptibility to Fusarium ear rot in field corn. Plant Dis. 78:517-519.

14. Jayaraman, S., and Parihar, D. B. 1975. Isolation of a growth promoting pigment from food grains infested with Fusarium moniliforme. Indian J. Exp. Biol. 13:313-314.

15. Jones, R. K. 1987. The influence of cultural practices on minimizing the development of aflatoxin in field maize. Pages 119-129 in: Aflatoxins in Maize: Proc. Workshop. M. S. Zuber, E. B. Lillihoj, and B. L. Renfro, eds. CIMMYT, Mexico, D.F.

16. Kedera, C. J., Leslie, J. F., and Claflin, L. E. 1992. Systemic infection of corn by F. moniliforme. (Abstr.) Phytopathology 82:1138.

17. King, S. B. 1981. Time of infection of maize kernels by Fusarium monili- 
forme and Cephalosporium acremonium. Phytopathology 71:796-799.

18. Kling, J. G., and Bosque-Pérez, N. A. 1995. Progress in screening and breeding for resistance to the maize stem borers Eldana saccharina and Sesamia calamistis. Pages 182-186 in: Maize Research for Stress Environments. Proc. 4th E. S. Afr. Regional Maize Conf. D. C. Jewell, S. R. Waddington, J. K. Ransom, and K. V. Pixley, eds. CIMMYT, Mexico, D.F.

19. Kling, J. G. Yallou, C. G., Kossou, D. K., Okoruwa, A. E., and Akintunde, A. O. 1997. Development of a high-yielding maize variety with good dry milling and storage properties in Benin Republic. Pages 199-207 in: Post Harvest Technology and Commodity Marketing. R. S. B. Ferris, ed. International Institute of Tropical Agriculture, and Silsoe College, Cranfield University, UK.

20. Koehler, B. 1942. Natural mode of entrance of fungi into corn ears and some symptoms that indicate infection. J. Agric. Res. 64:421-442.

21. Kommendahl, T., and Windels, C. E. 1981. Root-, stalk-, and ear-infecting Fusarium species on corn in the USA. Pages 94-103 in: Fusarium: Diseases, Biology, and Taxonomy. P. E. Nelson, T. A. Toussoun, and R. J. Cook, eds. The Pennsylvania State University, University Park.

22. Kossou, D. K., Mareck, J. H., and Bosque-Pérez, N. A. 1993. Comparison of improved and local maize varieties in the Republic of Benin with emphasis on susceptibility to Sitophilus zeamais Motschulsky. J. Stored Prod. Res. 29:333-343.

23. Lillehoj, E. B. 1987. The aflatoxin-in-maize problem: The historical perspective. Pages 13-33 in: Aflatoxins in Maize: Proceedings of the Workshop. M. S. Zuber, E. B. Lillihoj, and B. L. Renfro, eds. CIMMYT, Mexico, D.F.

24. Lillehoj, E. B., Kwolek, W. F., Guthrie, W. D., Barry, D., McMillian, W. W., and Widstrom, N. W. 1982. Aflatoxin accumulation in pre-harvest maize kernels: Interaction of three fungal species, European corn borer and two hybrids. Plant Soil 65:95-102.

25. Littell, R. C., Milligen, G. A., Stroup, W. W., and Wolfinger, R. D., 1996. SAS System for Mixed Models. SAS Institute, Inc., Cary, NC.

26. Marasas, W. F. O., Kriek N. P. J., Wiggins, V. M., Steyn, P. S., Towers, D. K., and Hastie, T. J. 1979. Infection, geographic distribution, and toxigenicity of Fusarium species in South African corn. Phytopathology 69:1181-1185

27. Marsh, S. F., and Payne, G. A. 1984 Preharvest infection of corn silks and kernels by Aspergillus flavus. Phytopathology 74:1284-1289.

28. McMillian, W. W. 1983. Role of arthropods in field contamination. Pages 20-22 in: Aflatoxin and Aspergillus flavus in Corn. U. L. Diener, R. L. Asquith, and J. W. Dickens, eds. S. Coop. Ser. Bull. 279. Auburn University, Alabama.

29. Meikle, W. G. C., Adda, K., Azoma, C., Borgemeister, P., Degbey, Djomamou, B., and Markham, R. H. 1998. The effects of maize variety on the density of Prostephanus truncatus (Col.: Bostrichidae) and Sitophilus zeamais (Col.: Curculionidae) in grain stores in Benin Republic. J. Stored Prod. Res. 34:45-58.

30. Miller, J. D. 1994. Epidemiology of Fusarium ear diseases of cereals. Pages 19-36 in: Mycotoxins in Grain-Compounds Other Than Aflatoxins. J. D. Miller and R. Trenholm, eds. Eagan Press, St. Paul, MN.

31. Munkvold, G. P., and Carlton, W. M. 1997. Influence of inoculation method on systemic Fusarium moniliforme infection of maize plants grown from infected seeds. Plant Dis. 81:211-216.

32. Munkvold, G. P., and Desjardins, A. E. 1997. Fumonisins in Maize: Can we reduce their occurrence? Plant Dis. 81:556-566.

33. Nelson, S. O. 1980. Moisture dependent kernel and bulk density for wheat and corn. Trans. ASAE 23:139-143.

34. Nelson, P. E., Toussoun, T. A., and Marasas W. F. O. 1983. Fusarium species: An Illustrated Manual for Identification. The Pennsylvania State University Press, University Park.

35. Odvody, G. N., Spencer, N., and Remmers, R. 1997. A description of silk cut, a stress-related loss of kernel integrity in preharvest maize. Plant Dis. 81:439-444.

36. Ooka, J. J., and Komendahl, T. 1977. Wind and rain dispersal of $F u$ sarium moniliforme in corn fields. Phytopathology 67:1023-1026.

37. Pomeranz, Y., Czuchajowska, Z., and Lai, F. S. 1986. Gross composition of coarse and fine fractions of small corn samples ground on the Stenvert Hardness Tester. Cereal Chem. 63:22-26.

38. Sandhu, S. S., Rajak, R. C., and Agarwal, G. P. 1993. Microbial control agents of forest pests at Jabalpur. Ann. For. 1:136-140.

39. Scott, G. E., and Zummo, N. 1987. Host plant resistance, screening methods. Pages 221-233 in: Aflatoxins in Maize: Proceedings of the Workshop. M. S. Zuber, E. B. Lillihoj, and B. L. Renfro, eds. CIMMYT, Mexico, D.F.

40. Seitz, L. M., Sauer, D. B., Mohr, H. E., and Aldis, D. F. 1982. Fungal growth and dry matter loss during bin storage of high-moisture corn. Cereal Chem. 59:9-14.

41. Sétamou, M., Cardwell, K. F., Schulthess, F., and Hell, K. 1997. Aspergillus flavus infection and aflatoxin contamination of preharvest maize in Benin. Plant Dis. 81:1323-1328.

42. Sétamou, M., Cardwell, K. F., Schulthess, F., and Hell, K. 1998. Effect of insect damage to maize ears, with special reference to Mussidia nigrivenella (Lepidoptera; Pyralidae), on Aspergillus flavus (Deuteromycetes; Monoliales) infection and aflatoxin production in maize before harvest in the Republic of Benin. J. Econ. Entomol. 91:433-438.

43. Smith, M. E., Mihm, J. A., and Jewell, D. C. 1989. Breeding for multiple resistance to temperate subtropical, and tropical maize insect pests at CIMMYT. Pages 22-234 in: Toward Insect Resistant Maize for the Third World. Proc. Int. Symp. Methodol. Develop. Host Plant Resistance to Maize Insects. CIMMYT, Mexico, D.F.

44. Snijders, C. H. A. 1994. Breeding for resistance to Fusarium in wheat and maize. Pages 37-59 in: Mycotoxins in Grain-Compounds Other than Aflatoxins. J. D. Miller and R. Trenholm, eds. Eagan Press, St. Paul, MN.

45. Srinivas, P. R., and Pasalu, I. C. 1990. Occurrence of a fungal disease on brown planthopper of rice. J. Biol. Control. 4:67.

46. Thomas, F., Eppley, R. M., and Trucksess, M. W. 1975. Rapid screening method for aflatoxins and zearalenone in corn. J. Assoc. Off. Anal. Chem. 58:114-116.

47. Tucker, D. H., Jr., Trevathan, L. E., King, S. B., and Scott, G. E. 1986. Effect of four inoculation techniques on infection and aflatoxin concentration of resistant and susceptible corn hybrids inoculated with Aspergillus flavus. Phytopathology 76:290-293.

48. Udoh, J. M., Ikotun, T., and Cardwell, K. F. 2000. Storage structures and aflatoxin content of maize in five agroecological zones of Nigeria. J. Stored Prod. Res. 36:187-201.

49. Warfield, C. Y., and Davis, R. M. 1996. Importance of the husk covering on the susceptibility of corn hybrids to Fusarium ear rot. Plant Dis. 80: 208-201.

50. Wicklow, D. T. 1994. Pre-harvest origins of toxigenic fungi in stored grain. Pages 1075-1081 in: Stored Product Protection. Proc. 6th Int. Working Conf. Stored-Product Prot. E. Highley, E. J. Wright, H. J. Banks, and B. R. Champ, eds. CAB International, Wallingford, UK.

51. Widstrom, N. W. 1987. Breeding strategies to control aflatoxin contamination of maize through host plant resistance. Pages 212-220 in: Aflatoxin in Maize: Proc. Workshop. M. S. Zuber, E. B. Lillehoj, and B. L. Renfro, eds. CIMMYT, Mexico, D.F.

52. Wilson, D. M., McMillan, W. W., and Widstrom, N. W. 1984. Differential effects of Aspergillus flavus and A. parasiticus on survival of Heliothis zea (Boddie) and Spodoptera frugiperda (J. E. Smith) (Lepidoptera: Noctuidae) reared on inoculated diet. Environ. Entomol. 13:100-104.

53. Wischer, W. R. 1961. The world of corn processing. Am. Miller Proc 89:23. 